\title{
Role of long non-coding RNAs and related epigenetic mechanisms in liver fibrosis (Review)
}

\author{
NILADRI GANGULY and SUBRATA CHAKRABARTI \\ Department of Pathology and Laboratory Medicine, University of Western Ontario, \\ London, ON N6A 5C1, Canada
}

Received July 11, 2020; Accepted October 29, 2020

DOI: $10.3892 /$ ijmm.2021.4856

\begin{abstract}
Liver fibrosis is one of the major liver pathologies affecting patients worldwide. It results from an improper tissue repair process following liver injury or inflammation. If left untreated, it ultimately leads to liver cirrhosis and liver failure. Long non-coding RNAs (IncRNAs) have been implicated in a wide variety of diseases. They can regulate gene expression and modulate signaling. Some of the lncRNAs promote, while others inhibit liver fibrosis. Similarly, other epigenetic processes, such as methylation and acetylation regulate gene transcription and can modulate gene expression. Notably, there are several regulatory associations of lncRNAs with other epigenetic processes. A major mechanism of action of long non-coding RNAs is to competitively bind to their target microRNAs (miRNAs or miRs), which in turn affects miRNA availability and bioactivity. In the present review, the role of IncRNAs and related epigenetic processes contributing to liver fibrosis is discussed. Finally, various potential therapeutic approaches targeting lncRNAs and related epigenetic processes, which are being considered as possible future treatment targets for liver fibrosis are identified.
\end{abstract}

\section{Contents}

1. Introduction

2. Regulation of liver fibrosis by lncRNAs

3. Modulation of signaling pathways by lncRNAs

4. Regulation of liver fibrosis by other epigenetic mechanisms

5. Interplay between histone and DNA methylation in liver fibrosis

6. Interactions of lncRNAs with other epigenetic mechanisms

Correspondence to: Professor Subrata Chakrabarti, Department of Pathology and Laboratory Medicine, University of Western Ontario, Dental Sciences Building, 1151 Richmond Street, London, ON N6A 5C1, Canada

E-mail: subrata.chakrabarti@lhsc.on.ca

Key words: non-coding RNAs, liver fibrosis, epigenetics, methylation, acetylation, therapy
7. Other considerations

8. Conclusions

\section{Introduction}

Hepatic fibrosis results from an aberrant wound healing process in the liver. In general, fibrosis results from an accumulation of extracellular matrix (ECM) proteins. Pathogenetically, apart from the abnormal deposition of ECM proteins, the improper degradation of ECM proteins also occurs $(1,2)$. Liver fibrosis results from persistent wound repair and regenerative processes due to continued hepatic injury caused by chronic liver diseases, such as non-alcoholic steatohepatitis (NASH), the excessive consumption of alcohol, hepatitis $\mathrm{B}$ and $\mathrm{C}$ infection, obstruction in the bile ducts, etc. $(3,4)$, ultimately leading to cirrhosis and predisposing affected patients towards the development of malignancies, such as hepatocellular carcinoma (HCC) (4-7). Although extensive research has been made into liver fibrosis (as discussed below), the mechanisms governing the process are not yet fully understood.

Hepatic stellate cells (HSCs), which are primarily involved in growth, regeneration and differentiation comprise $5-8 \%$ of total liver cells (8). The activation of HSCs is a key step in liver fibrosis, as it leads to the accumulation of the ECM proteins, $\alpha$-smooth muscle actin ( $\alpha$-SMA) and type I collagen $(9,10)$. Non-activated or quiescent HSCs lose their vitamin A stores and transdifferentiate into fibrogenic myofibroblast-like cells following liver injury (11-14). Therefore, the suppression of HSC activation is crucial for the therapy of liver fibrosis.

Transcriptome analysis, gene expression profiling by microarray and RNA sequencing have increasingly pointed to the role of non-coding RNAs (ncRNAs) as crucial regulators of gene expression and signal transduction (15). In liver carcinogenesis and fibrosis, ncRNAs have emerged as key regulators of gene expression (16-18). Therefore, ncRNAs may also be viewed as putative biomarkers for diagnosis and therapeutic targets for the treatment of liver fibrosis. Among the ncRNAs, major players include microRNAs (miRNAs or miRs) and long non-coding RNAs (lncRNAs). lncRNAs with sizes of $\geq 200$ nucleotides, are categorized into 4 subgroups as follows: Exonic, intronic, intergenic and bidirectional, depending on their placement and orientation with respect to protein coding genes. In liver fibrosis, lncRNAs may act as 
competitive endogenous RNAs (ceRNA), sponging miRNAs. This action releases the inhibition imposed by miRNAs on mRNA translation, thereby indirectly regulating gene expression. Other members of the ncRNA group include circular RNAs, PIWI-interacting RNAs, etc. (19).

Epigenetics encompass the changes in gene expression, that do not involve mutations in the DNA sequence. Epigenetic alterations are long-lasting and are heritable. Epigenetic alterations bring about changes in DNA properties along with transcriptional regulation. The epigenetic regulation of genes is significant in terms of gene expression and physiological function. Furthermore, epigenetic alterations are key pathogenetic mechanisms involved in various, if not all chronic diseases (20) involving all organs, such as skeletal muscle (21), the brain (22), heart (23), ovaries (24) and bones (25).

Epigenetic regulators can turn 'on or off' the expression of genes, depending on the prevailing microenvironment. Along with ncRNAs, other epigenetic processes include DNA and histone methylations and other biochemical mechanisms, causing alterations of DNA and histones. Such processes control several biological processes, such as genome imprinting, transposon mediated gene silencing, $\mathrm{X}$ chromosome inactivation, etc. (26). DNA methylation is catalyzed by DNA methyltransferases (DNMT). There are 3 DNMTs, namely DNMT1, DNMT3a and DNMT3b. Histone methylation is carried out as a balancing act between histone methyltransferase and histone dimethyl transferase (26). Additional epigenetic histone modification involves the addition/removal of acetyl groups on histone proteins. Histone acetylation is carried out by a group of enzymes known as histone acetyl transferases (HATs) and deacetylation is carried by histone deacetylases (HDACs). These 2 enzymes play important regulatory roles in HSC activation and the development of liver fibrosis (27). Other less well-studied mechanisms include ubiquitination, NEDDylation and SUMOylation. The targeting of ubiquitin enzymes has been shown to improve the physiology in liver fibrosis (28). Transforming growth factor- $\beta$ (TGF- $\beta$ ) is a cytokine secreted by the immune system. It has been demonstrated that the TGF- $\beta$ signaling pathway plays a crucial role in the development and progression of liver fibrosis (29). The dynamic interactions of lncRNAs with various pathways, such as miRNAs, DNA, histone methylation and histone acetylation are illustrated in Fig. 1.

The present review focuses on the role of IncRNAs in the promotion and inhibition of liver fibrosis. Furthermore, the interaction of lncRNAs with signaling pathways and the regulation of liver fibrosis through DNA methylation and acetylation is explored. The present review also discusses possible therapeutic implications of such processes in the treatment of liver fibrosis.

\section{Regulation of liver fibrosis by IncRNAs}

The transcriptome profiling of quiescent and activated HSCs lead to a better understanding of the mechanistic roles of IncRNAs in the promotion or inhibition of liver fibrosis $(30,31)$. A large volume of data have been obtained from the genome-wide screening of HSCs and tissues from human and animal models with respect to the expression patterns of lncRNAs. Understanding these expression patterns and their resulting regulation of cellular pathways are important for the development of targeted therapies for liver fibrosis. As will be evident from the discussions below, IncRNAs play diverse roles in mediating liver fibrosis. Some function as activators of liver fibrosis, whereas others may exert inhibitory effects. In addition, some of them may also play a dual role.

IncRNAs as activators of liver fibrosis. IncRNAs which activate liver fibrosis are usually upregulated or overexpressed in liver tissues affected by fibrosis. These IncRNAs activate HSCs and promote ECM protein overexpression. Several of these lncRNAs also activate the TGF- $\beta$ signaling pathway. As they are all upregulated, a potential therapeutic approach under consideration is lncRNA blockade using a small molecule or siRNA. The discussions below focus on specific lncRNAs and their roles in such processes.

The IncRNA, nuclear paraspeckle assembly transcript-1 (NEAT-1), may act as a miRNA sequestrating agent. In a recent study, it was found that NEAT-1 regulated the localization of miR-29b to the cytoplasm (32). Insulin like growth factor binding protein related protein 1 (IGFBPrP1) interacts with the TGF- $\beta$ signaling pathway to promote liver fibrosis (33). IGFBPrP1 induces the activation and autophagy of HSCs, which is regulated by Atg9a and NEAT-1, while miR-29b inhibits such a process (31), indicating that the NEAT-1/Atg9a/miR-29b pathway regulates liver fibrosis. NEAT-1 overexpression and its downstream effects on liver fibrosis are further prevented by Kruppel like factor 6 (KLF6) knockdown and miR122 overexpression (34). Therefore, NEAT-1/miR-122/KLF6 may function as another regulatory mechanism for liver fibrosis, modulating multiple signaling pathways.

Hox transcript antisense RNA (HOTAIR) has been found to be overexpressed in carbon tetrachloride (CCL4)-induced liver fibrosis in human and mouse models (30). HOTAIR binds to miR-148b and regulates the DNMT1/MEG3/p53 pathway in HSCs (35). It has also been reported that the HOTAIR-mediated downregulation of miR-29b attenuates its epigenetic control, inducing the hypermethylation of the phosphatase and tensin homolog (PTEN) gene, resulting in the progression of liver fibrosis (36). It is of further interest to note that one miRNA; i.e, miR29b, may regulate multiple, seemingly unrelated lncRNAs, such as NEAT-1 and HOTAIR, leading to the development of hepatic fibrosis.

Hox A distal transcript (HOTTIP) is a lncRNA which promotes HSC activation and fibrosis by functiong as a competitive endogenous RNA (ceRNA) for miR-148a and miR-150, and inducing the expression of serum response factor (SRF) (37). High HOTTIP levels reduce the expression of miR-148a, removing its inhibitory effects and thus increasing levels of TGF- $\beta$ receptor type 1 (TGFBR 1 ) and receptor 2 (TGFBR2), thereby promoting liver fibrosis (38).

Metastasis-associated lung adenocarcinoma transcript 1 (MALAT1) expression has been found to be upregulated in liver fibrosis; MALAT1 regulates the expression of sirtuin 1 (SIRT1), which deacetylates Smad3, a mediator of the TGF- $\beta$ signaling pathway and inhibits its binding to its target genes like collagen type 1 promoter (39). Through such an activation of SIRT1, the downregulation of the TGF- $\beta$ signaling pathway and the inhibition of liver fibrosis may occur. MALAT1 also induces mouse HSC activation via the regulation of RAS-Rac1 


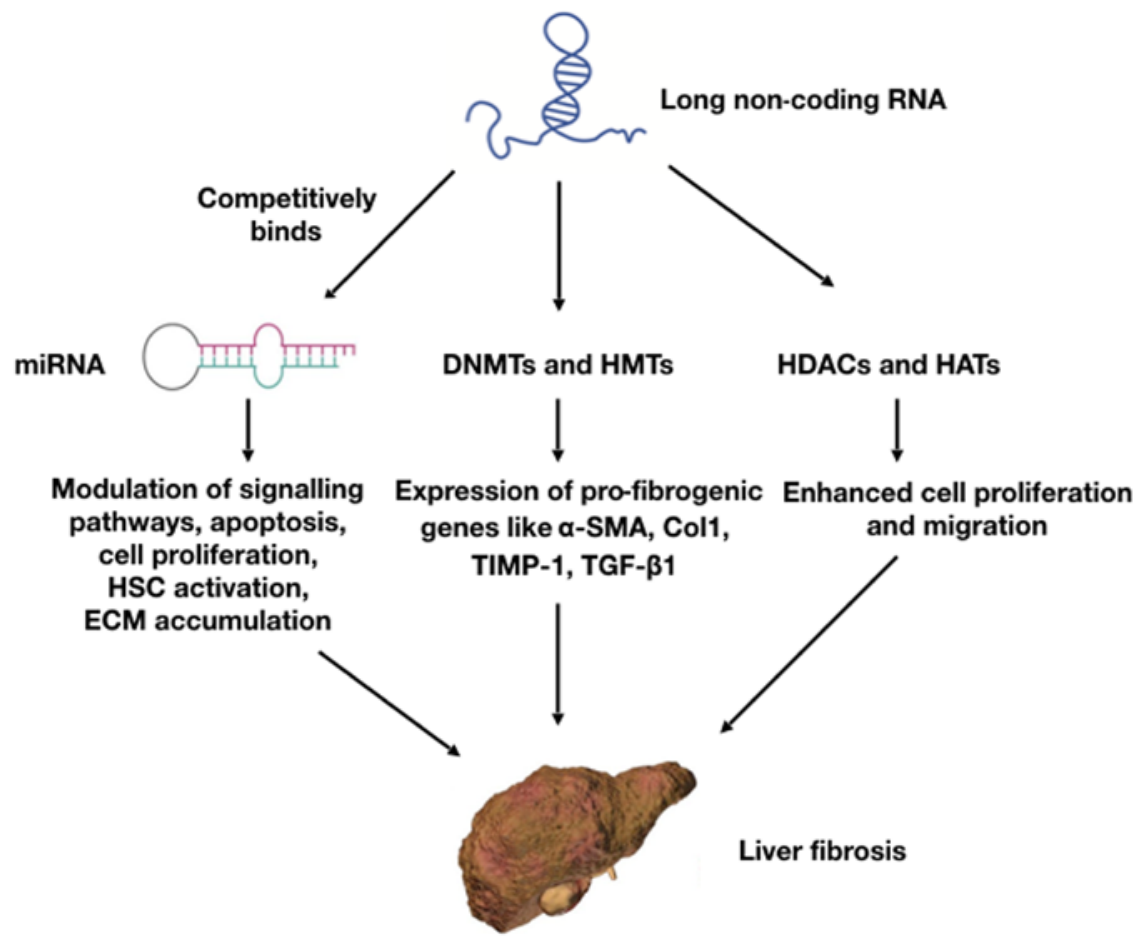

Figure 1. Mode of action of IncRNAs through different pathways for the development and progression of liver fibrosis. IncRNAs competitively bind to miRNAs and sequester them out of normal function. IncRNAs also affect epigenetic mechanisms, such as DNA and histone methylation by regulating the epigenetic enzymes, such as DNMTs. IncRNAs, long non-coding RNAs; miRNAs, microRNAs; DNMTs, DNA methyltransferases; HMTs, histone methyl transferases; $\alpha$-SMA, $\alpha$-smooth muscle actin.

by functioning as a ceRNA for miR-101b (40). In patients with NASH, MALAT1 has been found to be highly upregulated compared to normal tissues (41). MALAT1 can aggravate liver fibrosis through the generation of inflammatory chemokines, such as CXCL5 (41). Therefore, MALAT1, through its effects on the inflammatory processes, may modulate liver fibrosis.

Highly upregulated in liver cancer (HULC) plays an important role in liver fibrosis. HULC promotes liver fibrosis and is upregulated in tissues affected by non-alcoholic fatty liver disease (NAFLD) in rat models (42). The inhibition of HULC by siRNA results in the improvement of liver fibrosis and reduces the apoptosis of hepatocytes through the inhibition of the MAP kinase (MAPK) signaling pathway (42).

Small cajal body specific RNA 10 (SCARNA10) is a lncRNA which is elevated in serum and tissues of patients with liver fibrosis. It has also been shown to be upregulated in liver tissues in a mouse model of liver fibrosis (43). SCARNA10 is a positive regulator of the TGF- $\beta$ signaling pathway and inhibits polycomb repressive complex 2 (PRC2), which blocks TGF- $\beta$ signaling (43). TGF- $\beta$, TGF- $\beta$ R 1 , Smad2, Smad 3 and KLF6 levels decline upon SCARNA10 silencing (43).

Liver enriched fibrosis associated IncRNA 1 (LFAR1) is known to promote liver fibrosis. It has been demonstrated that TGF- $\beta$-induced hepatocyte apoptosis, CCL4-induced fibrosis and HSC activation are reduced upon lnc-LFAR1 silencing (44). LFAR1 directly binds to the Smad $2 / 3$ complex in the cytoplasm, and activates the TGF- $\beta$ and NOTCH pathways (44). Another lncRNA, SCRG1, is also highly upregulated in fibrotic human liver tissues (45). SCRG1 binds to RNA binding protein tristetraprolin (TTP) and accelerates liver fibrosis (45). The overexpression of TTP leads to the reduction of lncRNA SCRG1 and increases the degradation of matrix metallopeptidase 2 (MMP2) and TNF- $\alpha$ mRNAs, and vice versa (45).

In humans, small nuclear RNA host gene 7 (SNHG7) is significantly upregulated in fibrotic liver tissues (45). The knockdown of SNHG7 prevents HSC activation and collagen overproduction (46). SNHG7 binds to miR-378a-3p. Blocking miR-378a-3p production releases its inhibitory effects on liver fibrosis induced by SNHG silencing. SNHG7 further activates the $\mathrm{Wnt} / \beta$-catenin pathway to promote liver fibrosis. miR-378a-3p targets disheveled segment polarity 2 (DVL2) protein, which is a component of the SNHG7-mediated $\mathrm{Wnt} / \beta$-catenin pathway of liver fibrosis (46).

Plasmocytoma variant translocation 1 (PVT1) is a lncRNA which is upregulated in fibrotic liver tissues and activates HSCs (47). PVT1 knockdown reduces type I collagen and $\alpha$-SMA levels and inhibits HSC activation (47). PVT1 competitively binds to miR-152 and inhibits patched 1 (PTCH1) expression, which in turn activates the Hedgehog pathway, and promotes cell migration and liver fibrosis (47). Activated by transforming growth factor beta (ATB) is a lncRNA which is upregulated in hepatitis $\mathrm{C}$ virus ( $\mathrm{HCV}$ )-mediated liver fibrosis. ATB silencing induces the aberrant expression of miR-200a and reduces $\beta$-catenin expression, thereby suppressing HSC activation (48).

lincRNA-p21 is overexpressed during liver fibrosis (49) and promotes liver fibrosis by acting as a downstream effector of the TGF- $\beta$ signaling pathway by binding to miR-30 (49). In hepatocytes, the knockdown of lncRNA-p21 suppresses CCL4-induced liver fibrosis and inflammation; however, the ectopic expression of miR-30 promotes 
liver fibrosis (49). IncRNA-p21 also binds to miR-17-5p and inhibits the Wnt/ $\beta$-catenin pathway (50). It can modulate the miR-181b/PTEN cascade (51) and inhibit HSC proliferation through p21 (52). IncRNA-p21 has also been shown to be a potential biomarker of fibrosis in patients with hepatitis $B$ infection (53).

IncRNAs as inhibitors of liver fibrosis. There are several lncRNAs which act as suppressors of liver fibrosis; these are usually downregulated in liver fibrosis, and inhibit HSC activation and migration. Conceptually, they can be used as biomarkers. Furthermore, therapeutic strategies involving the overexpression of these RNAs may potentially be a therapeutic approach for liver fibrosis.

Maternally expressed gene 3 (MEG3) is a lncRNA which is significantly downregulated in human liver fibrosis and CCL4-induced fibrosis in experimental models (54). MEG3 prevents fibrosis following TGF- $\beta 1$-induced LX-2 cell activation. The overexpression of MEG3 in TGF- $\beta 1$-stimulated LX-2 cells induces p53 activation, cytochrome $c$ release and apoptosis (54). The overexpression of MEG3 also reduces $\alpha$-SMA and type I collagen levels. Furthermore, as circulating serum MEG3 levels are negatively associated with liver fibrosis in patients with hepatitis, it may further be a useful diagnostic marker (55). Smoothened (SMO) is involved in Hedgehog pathway for EMT; MEG3 binds to SMO and reduces EMT and thereby inhibits HSC activation (56). miR-212 targets MEG3 and acts as a negative regulator of MEG3. Hence, MEG3 possibly regulates EMT and HSC activation through SMO and miR-212. Growth arrested specific transcript 5 (GAS5) is a lncRNA, the expression of which is reduced in fibrotic liver tissues of mice, rats and humans (57). The overexpression of GAS5 inhibits collagen production and HSC activation. GAS5 acts as a ceRNA for miR-222 in the cytoplasm and increases the levels of p27 tumor suppressor protein, leading to suppressed HSC activation and proliferation (57). GAS5 also acts as a ceRNA for miR-23 in CCL4-induced liver fibrosis and increases miR-23 expression, leading to PTEN inhibition, resulting in the activation of the phosphatidyl-3 kinase/protein kinase B/mammalian target of rapamycin/Snail (PI3K/Akt/mTOR/Snail) pathway (8). Overall, it appears that GAS5/miR-222/p27 and GAS5/miR-23/PI3K/Akt/mTOR/Snail pathways play regulatory roles in this process.

Gm5091 is an intergenic lncRNA which is downregulated in mouse hepatic stellate cells during alcohol-induced hepatic fibrosis (58). Gm5091 binds to miR-27b/23b/24 and negatively regulates cell migration, ROS production, IL-1 $\beta$ secretion, type I collagen expression and HSC activation markers, such $\alpha$-SMA and Desmin (58). IncRNA hypoxia inducible factor 1A-antisense RNA 1 (HIF1A-AS1) levels also significantly increase when ten-eleven translocation (TET) family protein TET3 is silenced in HSCs (59). The silencing of HIF1A-AS1 further promotes the proliferation of HSCs and suppresses apoptosis (59). Antisense noncoding RNA in the INK4 Locus (ANRIL) is an inhibitor of liver fibrosis and is negatively regulated by DNMT3A (60). In activated HSCs and liver fibrotic tissues, ANRIL is downregulated. The silencing of ANRIL by DNMT3A results in HSC activation and liver fibrosis (60). Conversely, the overexpression of ANRIL suppresses HSC activation and reduces the expression levels of
DNMT3a, Collal and $\alpha$-SMA, and inhibits adenosine monophosphate-activated protein kinase (AMPK) signaling (60).

lncRNAs with regulatory dual roles in liver fibrosis. IncRNA $\mathrm{H} 19$ is involved in the regulation of cell proliferation and differentiation. It is genetically imprinted, maternally expressed and conserved in mice and humans (61). H19 is upregulated in human liver diseases and animal models of critical limb ischemia $(62,63)$. H19 plays a dual role liver fibrosis (both an inhibitory and promoting role) through distinct cellular targets. The inhibitory roles of H19 in liver fibrosis involve its effects on DNA methylation. In activated HSCs and rat liver fibrotic tissue, the reduced expression of H19, coupled with the elevated expression of DNMT1 and the increased methylation of H19 promoter are present (64). The silencing of H19 in HSCs increases the expression of phospho-extracellular signal regulated kinases $1 / 2$ (p-ERK1/2) (65). Methyl CpG binding protein 2 (MeCp2) is upregulated liver fibrosis and in activated HSCs. In a rat model of liver fibrosis, the overexpression of $\mathrm{MeCp} 2$ has shown to reduce $\mathrm{H} 19$ levels and the knockdown of MeCp2 leads to increased levels of H19 (65). The silencing of MeCp2 blocks HSC proliferation. Furthermore, the overexpression of H19 downregulates insulin like growth factor 1 receptor (IGF1R) and vice versa (65). Therefore, MeCp2 possibly targets IGF1R to promote liver fibrosis by negatively regulating $\mathrm{H} 19$ and the MeCp2/H19/IGF1R pathway $(64,65)$. $\mathrm{H} 19$ is further involved in the regulation of liver fibrosis in the context of cholestasis by modulating cell migration. Epithelial cell adhesion molecule (EpCAM) is negatively regulated by $\mathrm{E}$ box binding homeobox 1 (ZEB1) protein. In a mouse model of cholestatic liver fibrosis, H19 was shown to bind to ZEB1 to inhibit EpCAM expression and promote cell migration (66). In patients with biliary atresia (BA)-related liver fibrosis, H19 promotes cholangiocyte proliferation and cholestatic liver fibrosis via the regulation of sphingosine 1 phosphate receptor 2 (SIPR2)/sphingosine kinase 2 (SphK2) and the let-7/high mobility group AT-hook 2 (HMGA2) pathway (67). Cholangiocyte-derived H19-enriched exosomes induce the activation and differentiation of cultured HSCs and HSC-derived fibroblasts (68). Hence, the mechanisms of liver fibrosis involving H19 warrant further thorough investigations in order to develop therapeutic interventions for liver fibrosis modulating such processes. Various lncRNAs, their cellular targets and their roles in liver fibrosis are presented in Table I.

\section{Modulation of signaling pathways by lncRNAs}

As discussed above, lncRNAs are known to interact with and regulate multiple signaling pathways, such as TGF- $\beta$, p53, Hedgehog, PI3 kinase/Akt/mToR, Wnt/ $\beta$-catenin and MAP kinase, which dictate the initiation and progression of liver fibrosis $(12,69)$. The above-mentioned discussions outline some such pathways. The most well-studied pathway for liver fibrosis is the TGF- $\beta$ signaling pathway, which has been shown to interact with a number of lncRNAs. TGF- $\beta$ and its downstream effectors, such as Smad proteins control the progression of liver fibrosis, beginning from initial liver injury and inflammation (70-72). The regulation of liver 
Table I. IncRNAs in liver fibrosis.

\begin{tabular}{|c|c|c|c|}
\hline lncRNAs & Cellular target & Role in liver fibrosis & (Refs.) \\
\hline \multicolumn{4}{|c|}{ Activation of liver fibrosis } \\
\hline NEAT-1 & miR-122, miR-29b & $\begin{array}{l}\text { NEAT-1 promotes liver fibrosis through miR-122/KLF6 and } \\
\text { miR-29b/Atg9a pathways }\end{array}$ & $(31-34)$ \\
\hline HOTAIR & $\operatorname{miR}-148 b, \operatorname{miR}-29 b$ & $\begin{array}{l}\text { Acts as ceRNA for miR-148b, miR-29b. HOTAIR } \\
\text { regulates miR-148b/DNMT1/MEG3/p53 and miR-29b/PTEN } \\
\text { pathways in liver fibrosis }\end{array}$ & $(35,36)$ \\
\hline HOTTIP & miR-148a, miR-150 & $\begin{array}{l}\text { Acts as ceRNA for miR-148a and miR-150. Activates } \\
\text { TGF- } \beta \text { pathway and induces HSC activation }\end{array}$ & $(37,38)$ \\
\hline MALAT1 & miR-101b, miR-26b & $\begin{array}{l}\text { Promotes liver fibrosis through miR-26b/SIRT1/Smad3 } \\
\text { and miR-101b/Ras-Rac1 and CXCL5 pathways }\end{array}$ & $(39-41)$ \\
\hline HULC & $\begin{array}{l}\text { None } \\
\text { identified yet }\end{array}$ & $\begin{array}{l}\text { Silencing of HULC improves liver pathology in } \\
\text { NAFLD rats through inhibition of MAP kinase pathway }\end{array}$ & $(42)$ \\
\hline SCARNA10 & $\mathrm{PRC} 2$ & Positively regulates TGF- $\beta$ pathway by inhibiting PRC2 & (43) \\
\hline Lnc-LFAR1 & $\operatorname{Smad} 2 / 3$ & $\begin{array}{l}\text { Binds to } S m a d 2 / 3 \text { in cytoplasm to activate TGF- } \beta \text { and } \\
\text { NOTCH pathway. }\end{array}$ & $(44)$ \\
\hline Linc-SCRG1 & TTP & $\begin{array}{l}\text { Binds and inhibits TTP and prevents TTP induced } \\
\text { degradation of TNF- } \alpha \text { and MMP- } 2 \text {. }\end{array}$ & $(45)$ \\
\hline SNHG7 & $\operatorname{miR}-378 a-3 p$ & $\begin{array}{l}\text { Activates } \mathrm{Wnt} / \beta \text {-catenin pathway by negatively } \\
\text { regulating } \mathrm{miR}-378 \mathrm{a}-3 \mathrm{p}\end{array}$ & (46) \\
\hline PVT1 & miR-152 & $\begin{array}{l}\text { Binds as ceRNA to miR-152 which leads to PTCH1 } \\
\text { inhibition, resulting in activation of Hedgehog pathway } \\
\text { to promote cell migration and liver fibrosis }\end{array}$ & $(47)$ \\
\hline Lnc RNA-ATB & miR-200a & $\begin{array}{l}\text { ATB knockdown reduced } \beta \text {-catenin expression by upregulating } \\
\text { miR-200a expression and suppressed LX- } 2 \text { cells activation }\end{array}$ & $(48)$ \\
\hline LincRNA-p21 & $\begin{array}{l}\mathrm{p} 21, \mathrm{miR}-30 \\
\text { miR-181b, miR-17-5p }\end{array}$ & $\begin{array}{l}\text { Promotes liver fibrosis through multiple pathways involving } \mathrm{p} 21 \text {, } \\
\text { miR-181b/PTEN miR-17-5p/ } \beta \text {-catenin and miR-30 }\end{array}$ & $(49-53)$ \\
\hline \multicolumn{4}{|c|}{ Inhibition of liver fibrosis } \\
\hline MEG3 & miR-212, SMO & $\begin{array}{l}\text { Overexpression of MEG3 inhibited HSC activation, induced } \\
\text { hepatocyte apoptosis and reduced } \alpha \text {-SMA and type Icollagen }\end{array}$ & $(54-56)$ \\
\hline GAS5 & $\operatorname{miR}-23 \mathrm{a}, \mathrm{miR}-222$ & $\begin{array}{l}\text { Binds as a ceRNA to miR-23a and miR-222 to inhibit } \\
\text { PTEN and increase p27 levels respectively }\end{array}$ & $(8,57)$ \\
\hline Gm5091 & $\begin{array}{l}\operatorname{miR}-27 b, \operatorname{miR}-23 b \\
\operatorname{miR}-24\end{array}$ & $\begin{array}{l}\text { Alleviates alcoholic liver fibrosis by sequestration of } \\
\text { miR-23b, miR-27b, miR-24 and down regulation of } \\
\text { HSC activation, cell migration, type I collagen expression }\end{array}$ & $(58)$ \\
\hline HIF1-AS1 & TET3 & $\begin{array}{l}\text { HIF1-AS } 1 \text { inhibits LX-2 cell proliferation and is } \\
\text { negatively regulated by TET3 }\end{array}$ & $(59)$ \\
\hline ANRIL & DNMT3A, AMPK & Overexpression of ANRIL inhibits DNMT3A and AMPK & $(60)$ \\
\hline \multicolumn{4}{|c|}{ Dual role in liver fibrosis } \\
\hline \multirow[t]{2}{*}{ H19 } & MeCP2, IGF1R & $\begin{array}{l}\text { Overexpression of H19 inhibits liver fibrosis by } \\
\text { downregulating pERK1/2 and MeCP2/IGF1R pathways }\end{array}$ & $(64,65)$ \\
\hline & let7, ZEB1 & $\begin{array}{l}\text { Promotes cholestatic liver fibrosis by binding to ZEB1 } \\
\text { and inhibiting cell migration and activates } \\
\text { SIPR2/SphK2/let7/HMGA2 pathway }\end{array}$ & $(66-68)$ \\
\hline
\end{tabular}

The table lists several lncRNAs and their corresponding cellular targets. Most of these targets are miRNAs and in some cases, signaling proteins. Depending on their role in liver fibrosis, they have been categorized in to activators or inhibitors of liver fibrosis. lncRNAs, long non-coding RNAs; miRNAs, microRNAs.

fibrosis-related pathways by lncRNAs is illustrated in Fig. 2 . Some of these pathways promote liver fibrosis, while others suppress it.
The mechanisms of action by lncRNAs are usually directed through its complex secondary structures, and the ability to bind to other RNA and protein molecules. This endows them 


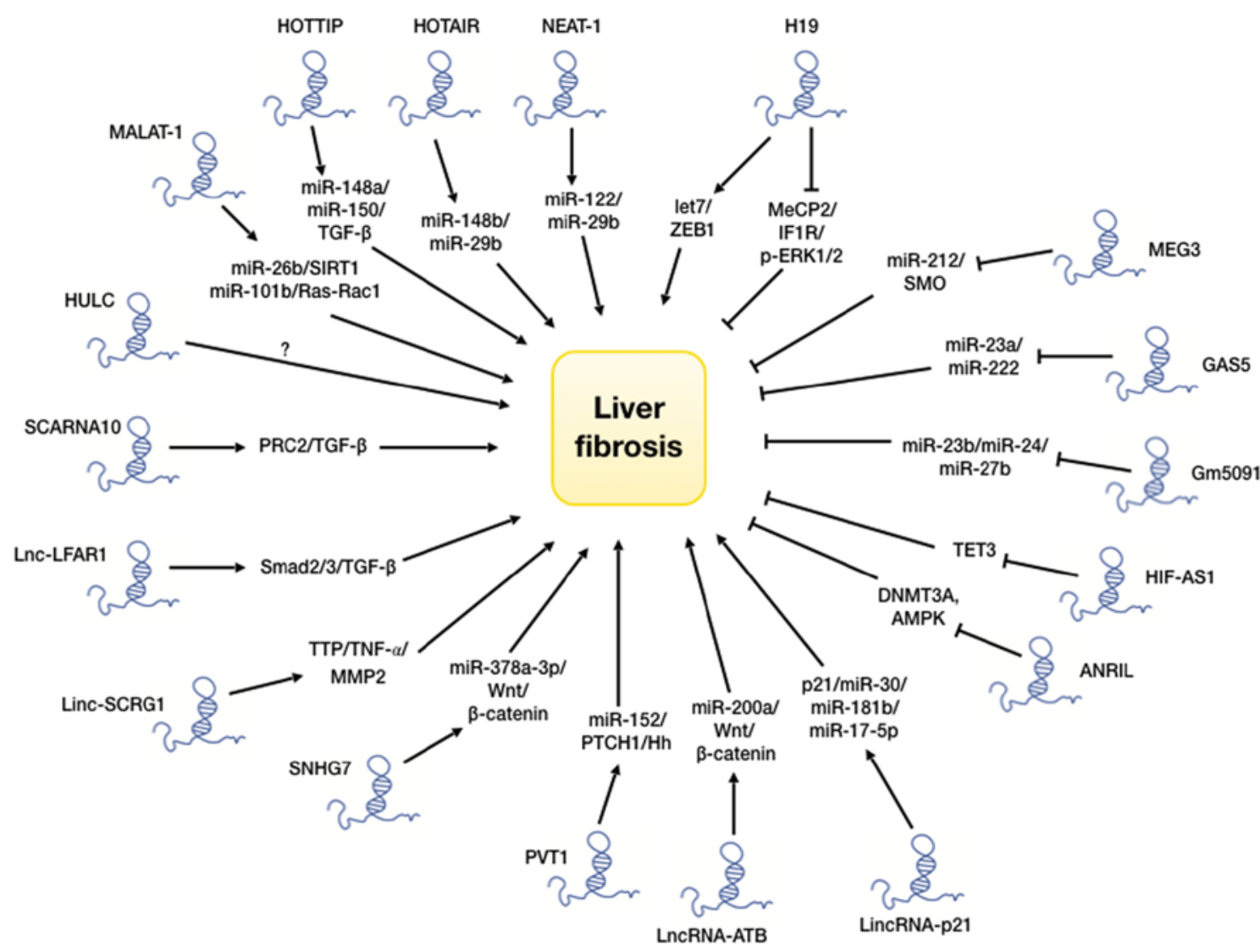

Figure 2. Diagram illustrating the mechanisms through which various lncRNAs mediate their effects through intermediate miRNAs and signaling molecules. IncRNAs modulate the functions of various miRNAs and cellular pathways, such as TGF-Smad, Wnt/ $\beta$-catenin, Hedgehog, SIRT1, ERK1/2, AMPK and TNF- $\alpha$. The second row of arrows indicate lncRNAs which are activators of liver fibrosiss, while the blocked line represents inhibitors of liver fibrosis. lncRNAs, long non-coding RNAs; miRNAs, microRNAs.

with both unique and diverse traits with which to regulate other molecules (73-76). There are broadly 2 types of mechanisms through which IncRNAs regulate the activity of the target molecule; firstly, acting as a ceRNA to bind to a miRNA through complementary base pairing and inhibiting the normal function of the miRNA; secondly, by directly binding to a signaling protein through its complex secondary structure and blocking/activating the protein function. An additional mechanism of lncRNA functions includes the binding to DNA to form a triple helical structure. This helical structure can function as a docking site for binding of proteins which can regulate gene expression (77). Recent advances in ncRNA studies have enabled their use as a diagnostic tool $(78,79)$. Circulating ncRNAs from patients with liver fibrosis may be quantified and monitored over the course of time as surrogate markers for disease progression (80). Studies on IncRNA-based therapy have also been successfully implemented in preclinical models (81). However, clinical trials to verify the efficacy and toxicity of these therapies remain to be performed, at least to the best of our knowledge. Nonetheless, lncRNAs may represent a novel molecular therapeutic approach for liver fibrosis.

\section{Regulation of liver fibrosis by other epigenetic mechanisms}

The epigenetic control of gene expression is a well-studied area. The present review focuses on DNA methylation, as well as histone methylation and acetylation. DNA methylation is one of the better understood epigenetic mechanisms. The methylation of DNA occurs at the cytosine residue located 5' to guanosine residue in a stretch of $\mathrm{CpG}$ dinucleotides termed $\mathrm{CpG}$ islands. The methylation of $\mathrm{CpG}$ stretches in the promoter region of a gene and is known to inhibit or repress gene expression. The methylation of cytosine residues prevents the binding of DNA binding proteins required for transcription (82). DNA methylation is carried out by a group of enzymes known as DNA methyltransferases (DNMTs), which are divided into 2 subcategories: Those involved in the de novo methylation of DNA (DNMT3a and DNMT3b) and those involved in maintenance of methylation patterns post-DNA replication (DNMT1) (83-87).

During the development of liver fibrosis, changes in patterns of DNA methylation, altered activity and the expression of associated enzymes have been observed. These changes are crucial for the establishment and progression of liver fibrosis (88-90). As previously demonstrated, activated cultured rat HSCs, when treated with the DNA methylation inhibitor, 5-aza, 2-deoxycytidine, have failed to differentiate into myofibroblasts (91). During HSC activation or trans-differentiation, a global DNA hypomethylation is observed $(92,93)$. Although there is an overall demethylation during HSC activation, genome-wide methylation studies have revealed that hypo- or hypermethylation occuring in the promoter region is specific to each gene (92). During HSC activation, the Wnt signaling pathway has been found to be epigenetically 
Table II. Epigenetic regulation of genes involved in liver fibrosis.

\begin{tabular}{|c|c|c|c|}
\hline Gene & Gene expression & Epigenetic mechanism involved & (Refs.) \\
\hline Apc2 & Upregulated & Hypomethylation of gene promoter & $(92-95)$ \\
\hline Wnt5a & & Hypomethylation of gene promoter & $(93-95)$ \\
\hline $\operatorname{Actg} 2$ & & Hypomethylation of gene promoter & $(87)$ \\
\hline Loxl1 & & Hypomethylation of gene promoter & (87) \\
\hline Loxl2 & & Hypomethylation of gene promoter & $(87)$ \\
\hline Col4al/2 & & Hypomethylation of gene promoter & $(87)$ \\
\hline Collal/2 & & H3K4 methylation by COMPASS and ASH1 & $(100,101)$ \\
\hline Elastin & & H3K4 methylation by MLL1 & $(98)$ \\
\hline$\alpha-S M A$ & & Transcriptional activation by p300 & $(100,101)$ \\
\hline$T G F-\beta 1$ & & H3K4 methylation by ASH1 HMT & $(100,101)$ \\
\hline TIMP-1 & & H3K4 methylation by ASH1 HMT & $(100,101)$ \\
\hline Adamts 9 & Downregulated & Hypermethylation of promoter DNA & $(95)$ \\
\hline$M M P-15$ & & Hypermethylation of promoter DNA & $(95)$ \\
\hline Smad7 & & Hypermethylation of promoter DNA & $(96)$ \\
\hline Pten & & Hypermethylation of promoter DNA & $(97)$ \\
\hline$P P A R-\gamma$ & & Hypermethylation of promoter DNA by EZH2 at H3K27 and G9a at H3K9 & $(105-107,131)$ \\
\hline
\end{tabular}

The table shows the epigenetic regulation of genes involved in liver fibrosis. Hypermethylation or hypomethylation of gene promoters can upregulate or downregulate the gene expression, respectively. Epigenetic enzymes and their targets are shown.

regulated; $A p c 2$ and $W n t 5 a$ are upregulated upon promoter hypomethylation (93-95). Similarly, pro-fibrogenic genes, such as Actg2, Loxl1, Loxl2 and Col4al are activated upon the hypomethylation of their respective promoters (87). Conversely, DNA hypermethylation causes the transcriptional repression in genes, such as Adamts9 and Mmpl5 (95), which produce matrix metalloproteinases involved in ECM breakdown and cell migration. Similarly, Smad7, TGF- $\beta$ R1 antagonist (96) and pro-apoptotic PTEN (97) are also negatively regulated by DNA hypermethylation.

DNMTs are not the only methylating agents in cells. The methylation of histones is another form of epigenetic regulatory mechanism. There are 2 types of histone regulatory enzymes; histone methyl transferases (HMTs) and histone demthyltransferases (HDMTs). Recent studies have indicated the roles of these enzymes in liver fibrosis. The exposure of HSCs to ethanol increases the expression of histone-3 lysine-4 (H3K4) methyl transferase, MLL1, which is recruited the promoter of the pro-fibrogenic elastin gene (98). The TGF- $\beta$ stimulation of mouse embryonic fibroblasts (MEFs) increases dimethylated (H3K4me2) and trimethylated (H3K4me3) histone levels in the promoters of the pro-fibrogenic genes, Colla1 and Colla2. $\mathrm{H} 3 \mathrm{~K} 4 \mathrm{me} 2$ and $\mathrm{H} 3 \mathrm{~K} 4 \mathrm{me} 3$ histone signatures are imprinted by a complex protein associated with Set1 (COMPASS). This protein complex COMPASS contains HMTs, such as ASH2 and SET1, which binds to the promoters of pro-fibrogenic genes upon the TGF- $\beta$ stimulation of HSCs and MEFs (98). ASH1 is also a HMT, which targets $\mathrm{H} 3 \mathrm{~K} 4$ methylation and is upregulated during HSC transdifferentiation (99). ASH1 binds to the promoters of $\alpha$-SMA, Colla1, TIMP- 1 and TGF- $\beta 1$, and causes the transcriptional activation of these genes $(100,101)$.

Enhancer of zeste homologue 2 (EZH2) further acts as a HMT, which is part of polycomb repressor complex 2 (PRC2) that cause H3K27 methylation and promotes the progression of liver fibrosis (102). In CCL4-mediated liver injury, EZH2 expression is increased in activated HSCs (103). The TGF- $\beta$ stimulation of HSCs can also induce EZH2 (104). The increased expression of EZH2 in activated HSCs causes H3K27 methylation in exons A1 and A2 of peroxisome proliferator activator receptor- $\gamma$ (PPAR- $\gamma$ ) causing transcriptional repression of PPAR- $\gamma(105,106)$. The methylation of exons leads to the recruitment of polycomb repressor complex 1 (PRC1) and causes chromatin condensation, thus preventing the transcriptional elongation of downstream exons (107). The downregulation of PPAR- $\gamma$ is necessary to enable HSC transdifferentiation into myofibroblasts. The epigenetic regulation of genes involved in liver fibrosis through methylation is presented in Table II. Histone acetylation/deacetylation is an important epigenetic mechanism which regulates gene expression and action. Studies have suggested a greater role of HDACs compared to HATs in HSC activation and fibrogenesis. Based on their structure and mechanisms of action, HDACs are grouped into 4 classes: Class I-HDAC1, 2, 3, 8; Class II-HDAC4, 5, 6, 7, 9, 10; Class III-Sirt 1-7; Class IV-HDAC11. During HSC activation, HDAC1 and 2 protein levels have been found to be downregulated (108). In a previous study, in the culture of primary HSCs, HDAC5 and 6 levels peaked at day 4 before decreasing back to baseline levels (109). It was further observed that the pharmacological or siRNA-mediated inhibition of class II HDACs resulted in the upregulation of anti-fibrotic miR-29 (110). The inhibition of HDACs reduced the levels of HSC activation markers e.g., $\alpha$-SMA, collagen and lysyl oxidase, and also inhibited cell proliferation (109). The inhibition of HDAC1, 2 and 4 by nilotinib has been shown to result in the increased apoptosis and autophagy of activated rat HSCs and human LX-2 cells (110). 
Cell death occurs in activated HSCs only, not quiescent ones. MMPs are metallopeptidases, which play an important role in liver injury and ECM accumulation (111). MMPs are produced by quiescent HSCs, which release growth factors required for wound healing and ECM production (112). However, their levels decrease during HSC transdifferentiation and in liver fibrosis. An interesting link has been found between MMPs and HDACs, which indicates that the ectopic expression of HDAC4 in quiescent HSCs suppresses Mmp9 and Mmpl3 gene expression (112). As lncRNAs are regulated in a similar manner as protein-coding genes, a regulatory asssociation of lncRNAs through acetylation is present (113-116). These studies have demonstrated that HDACs play a regulatory role in liver fibrosis and HSC activation, and may be considered as drug targets.

Pharmacological inhibitors of DNMTs, such as 5-azacytidine, decitabine, guadecitabine, etc. are being tested for the treatment of hematological cancers and for solid tumors, such as hepatocellular carcinoma (HCC) (117-119). These drugs have been shown to be reasonably effective in safety trials and may have potential for use in the treatment of liver fibrosis. Inhibitors of HDACs are also being used to treat malignancies. These inhibitors block cell proliferation and induce apoptosis, and also suppress HSC activation $(120,121)$. Largazole, an HDAC inhibitor, has been shown to suppress liver fibrogenesis and angiogenesis by inhibiting TGF- $\beta$ and VEGF signaling $(18,122)$. It has also been shown that sodium valproate, a class I and II HDAC inhibitor, when added to cultured HSCs, blocked TGF- $\beta$ signaling and downregulated TGF- $\beta$ induced Coll $\alpha 1$ expression (123). Trichostatin A (TSA), another HDAC inhibitor, has been shown to suppress HSC differentiation into myfibroblasts, and to downregulate $\alpha$-SMA, and type I and III collagen (124). In CCL4-induced liver fibrosis, TSA has been found to suppress HSC activation through the acetylation of CAAT/enhancer binding protein $\alpha$ (C/EBP- $\alpha)$ (125). These epigenetic inhibitors provide promising therapeutic targets for liver fibrosis.

\section{Interplay between histone and DNA methylation in liver fibrosis}

The histone code is defined as the epigenetic signature (methylation and/or acetylation) imprinted on histones. The expression of genes is regulated by chromatin remodeling, which in turn is regulated by epigenetic modifications. The interaction between DNA methylation and histone code represents a functional regulatory mechanism which influences chromatin structure $(126,127)$. The epigenetic modifications on DNA provides docking sites for many transcriptional regulatory proteins which determine gene expression.

Methyl CpG binding protein-2 (MeCP2) binds to methylated cytosine residues on stretches of $\mathrm{CpG}$ dinucleotides. $\mathrm{MeCP} 2$ regulates the expression of the $\alpha-S M A$ gene. MeCP2 knockout mice exhibit a reduced $\alpha-S M A$ expression and collagen deposition in alveolar cells $(128,129)$. Similar effects have been observed in liver fibrosis (103), establishing the role of $\mathrm{MeCP} 2$ in myofibroblast differentiation and liver fibrosis. One of the key steps in HSC transdifferentiation is the epigenetic repression of the $P P A R-\gamma$ gene, which inhibits $\mathrm{HSC}$ apoptosis and promotes fibrogenesis. MeCP2 binds to the $P P A R-\gamma$ promoter and methylates histone $\mathrm{H} 3 \mathrm{~K} 9$, thereby causing the transcriptional silencing of $P P A R-\gamma(103)$. MeCP2 also induces the expression of EZH2 histone methyl transferase, which methylates histone $\mathrm{H} 3 \mathrm{~K} 27$ as a part of PRC2 causing the silencing of PPAR- $\gamma$ (102). MeCP2 also induces the expression of histone methyl transferase ASH1, which activates the transcription of profibrogenic genes, such as $\alpha$-SMA, Colla1, TIMP-1 and TGF- $\beta 1$ during myofibroblast differentiation (103). Hence, a coordinated crosstalk between DNA methylation and the histone code, and the epigenetic enzymes can cause transcriptional activation or repression, depending on the specific molecular interactions near the promoters of target genes. MeCP2 causes the transcriptional repression of genes when it binds to 5-methyl cytosine whereas it activates gene expression when it binds to 5-hydroxymethyl cytosine $(130,131)$. It has been demonstrated that both DNMT1 and $\mathrm{H} 3 \mathrm{~K} 9$ methyl transferase inhibits $P P A R-\gamma$ by binding to its promoter during HSC activation (131), whereas the inhibition of DNMT1 and G9a results in PPAR- $\gamma$ upregulation and the suppression of HSC activation (131).

\section{Interactions of IncRNAs with other epigenetic mechanisms}

It is of interest to note that the production and/or action of lncRNAs are also regulated by DNA and histone methylation. For example, DNMT1 regulates the lncRNA H19/ERK signaling pathway, which promotes HSC activation and liver fibrogenesis (64). ANRIL is regulated by DNMT3a during HSC activation. DNMT3a suppresses ANRIL expression in activated HSCs with a concomitant increase in the expression of $\alpha$-SMA, Colla1 and AMPK and p-AMPK in rat and human model of liver fibrosis (60). MeCP2 as discussed above is an epigenetic regulator of pro and anti-fibrogenic genes. However, MeCP2 has also been reported to silence the expression of IncRNA H19 through the IGF1R pathway and to promote HSC proliferation (65). The pro-fibrogenic activity of MeCP2 is regulated by phosphorylation at Serine 80 and its deletion in HSCs results in the altered expression of 284 mRNAs and 244 lncRNAs (132). The understanding of the crosstalk between epigenetic regulators and lncRNAs may help to broaden our understanding of the pathogenesis and subsequent potential therapeutic approaches for liver fibrosis $(12,132)$. $\mathrm{EZH} 2$, which is a HMT, methylates H3K27 histone within the exons of PPAR $\gamma$ (102). The methylation of histones leads to the recruitment of the PRC1 complex, which causes the reorganization of the chromatin structure. The binding of PRC1 causes chromatin condensation, which prevents the binding of RNA polymerase II to the DNA template, causing premature termination of transcription (106), indicating that epigenetic mechanisms indirectly regulate gene expression by changing chromatin dynamics.

\section{Other considerations}

One of the main external stimuli that may affect epigenetic changes is the food that is consumed by an individual. The type of food, as well as the method through which food is prepared, may influence DNA and or histone damage, and subsequent epigenetic alterations, leading to alterations in gene expression. In addition, exposure to environmental 
toxins, such as smoking and other pollutants may also affect cells through epigenetic mechanisms (133). However, the detailed analyses of such an etiology and how the aforesaid changes are influenced, are beyond the scope of the present review. Similarly, as the present review focused on IncRNAs, miRNAs and their effects on liver fibrosis either directly or distally through an exosome-mediated mechanism were not addressed. A previously published review article has addressed this topic $(134,135)$.

\section{Conclusions}

The present review aimed to highlight the importance of lncRNAs in the initiation and progression of liver fibrosis. The present review also outlined how such processes are regulated by histone and DNA methylation and histone acetylation. The recent impetus into the study of lncRNAs has provided a clearer picture into their roles in HSC activation and liver fibrosis. However, the complex regulatory network of lncRNAs and their associations with a plethora of molecules, renders the elucidation of the underlying mechanisms challenging. A diagrammatic outline is illustrated in Fig. 2. As there may also be disease-specific variation, a therapeutic strategy may involve a combination of disease-specific targets. Furthermore, the majority of the studies have focused on HSCs and the potential contribution by other cells may also have to be investigated in order to obtain a better understanding of the mechanisms involved.

\section{Acknowledgements}

Not applicable.

\section{Funding}

NG received A fellowship from ICMR no. INDOiFRC/452 I (Y-U) t 201 g2UIHD, Government of India. SC received funding from CIHR grant no. 425360, Government of Canada.

\section{Availability of data and materials}

Not applicable.

\section{Authors' contributions}

Both authors (NG and SC) contributed equally to the conception, design, writing, and critical reviewing and reading of the manuscript. Both authors read and approved the final manuscript.

\section{Ethics approval and consent to participate}

Not applicable.

\section{Patient consent for publication}

Not applicable.

\section{Competing interests}

The authors declare that they have no competing interests.

\section{References}

1. Aydın MM and Akçalı KC: Liver fibrosis. Turk J Gastroenterol 29: 14-21, 2018.

2. Lan T, Li C, Yang G, Sun Y, Zhuang L, Ou Y, Li H, Wang G, Kisseleva T, Brenner D and Guo J: Sphingosine kinase 1 promotes liver fibrosis by preventing miR-19b-3p-mediated inhibition of CCR2. Hepatology 68: 1070-1086, 2018.

3. Bataller R and Brenner DA: Liver fibrosis. J Clin Invest 115: 209-218, 2005.

4. Karsdal MA, Hjuler ST, Luo Y, Rasmussen DGK, Nielsen MJ, Holm Nielsen S, Leeming DJ, Goodman Z, Arch RH, Patel K and Schuppan D: Assessment of liver fibrosis progression and regression by a serological collagen turnover profile. Am J Physiol Gastrointest Liver Physiol 316: G25-G31, 2019.

5. Chen L, Brenner DA and Kisseleva T: Combatting fibrosis: Exosome-based therapies in the regression of liver fibrosis. Hepatol Commun 3: 180-192, 2018.

6. Lledó GM, Carrasco I, Benítez-Gutiérrez LM, Arias A, Royuela A, Requena S, Cuervas-Mons V and de Mendoza C: Regression of liver fibrosis after curing chronic hepatitis $\mathrm{C}$ with oral antivirals in patients with and without HIV coinfection. Aids 32: 2347-2352, 2018.

7. Atta HM: Reversibility and heritability of liver fibrosis: Implications for research and therapy. World J Gastroenterol 21: 5138-5148, 2015.

8. Dong Z, Li S, Wang X, Si L, Ma R, Bao L and Bo A: lncRNA GAS5 restrains $\mathrm{CCl}_{4}$-induced hepatic fibrosis by targeting miR-23a through the PTEN/PI3K/Akt signaling pathway. Am J Physiol Gastrointest Liver Physiol 316: G539-G550, 2019.

9. Dou C, Liu Z, Tu K, Zhang H, Chen C, Yaqoob U, Wang Y, Wen J, van Deursen J, Sicard D, et al: P300 acetyltransferase mediates stiffness-induced activation of hepatic stellate cells into tumor-promoting myofibroblasts. Gastroenterology 154: 2209-2221.e14, 2018.

10. Brandon-Warner E, Benbow JH, Swet JH, Feilen NA, Culberson CR, McKillop IH, deLemos AS, Russo MW and Schrum LW: Adeno-associated virus serotype 2 Vector-mediated reintroduction of microRNA-19b attenuates hepatic fibrosis. Hum Gene Ther 29: 674-686, 2018.

11. Seki E and Schwabe RF: Hepatic inflammation and fibrosis: Functional links and key pathways. Hepatology 61: 1066-1079, 2015.

12. Peng H, Wan LY, Liang JJ, Zhang YQ, Ai WB and Wu JF: The roles of lncRNA in hepatic fibrosis. Cell Biosci 8: 63, 2018.

13. Campana L and Iredale JP: Regression of liver fibrosis. Semin Liver Dis 37: 1-10, 2017.

14. Knolle PA and Wohlleber D: Immunological functions of liver sinusoidal endothelial cells. Cell Mol Immunol 13: 347-353, 2016.

15. Heo MJ, Yun J and Kim SG: Role of non-coding RNAs in liver disease progression to hepatocellular carcinoma. Arch Pharm Res 42: 48-62, 2019.

16. Wei L, Wang X, Lv L, Liu J, Xing H, Song Y, Xie M, Lei T, Zhang $\mathrm{N}$ and Yang $\mathrm{M}$ : The emerging role of microRNAs and long noncoding RNAs in drug resistance of hepatocellular carcinoma. Mol Cancer 18: 147, 2019.

17. Zhou J, Li Y, Liu X, Long Y and Chen J: LncRNA-regulated autophagy and its potential role in drug-induced liver injury. Ann Hepatol 17: 355-363, 2018.

18. Yang Z, Jiang S, Shang J, Jiang Y, Dai Y, Xu B, Yu Y, Liang Z and Yang Y: LncRNA: Shedding light on mechanisms and opportunities in fibrosis and aging. Ageing Res Rev 52: 17-31, 2019.

19. Klinge CM: Non-coding RNAs in breast cancer: Intracellular and intercellular communication. Noncoding RNA 4: 40, 2018.

20. Zoghbi HY and Beaudet AL: Epigenetics and human disease. Cold Spring Harb Perspect Biol 8: a019497, 2016.

21. Sahu B, Pani S, Swalsingh G and Bal NC: Non and epigenetic mechanisms in regulation of adaptive thermogenesis in skeletal muscle. Front Endocrinol (Lausanne) 10: 517, 2019.

22. Ortuno-Sahagun D, Schleibs R and Pallas M: Editorial: Epigenetic mechanisms regulating neural plasticity. Front Cell Neurosci 13: 118, 2019.

23. Martinez SR, Gay MS and Zhang L: Epigenetic mechanisms in heart development and disease. Drug Discov Today 20: 799-811, 2015.

24. Maldonado L and Hoque MO: Epigenomics and ovarian carcinoma. Biomark Med 4: 543-570, 2010.

25. Vrtacnik P, Marc J and Ostanek B: Epigenetic mechanisms in bone. Clin Chem Lab Med 52: 589-608, 2014. 
26. Wu SC and Zhang Y: Active DNA demethylation: Many roads lead to Rome. Nat Rev Mol Cell Biol 11: 607-620, 2010.

27. Barcena-Varela M, Colyn L and Fernandez-Barrena MG: Epigenetic mechanisms in hepatic stellate cell activation during liver fibrosis and carcinogenesis. Int J Mol Sci 20: 2507, 2019.

28. Lachiondo-Ortega S, Mercado-Gómez M, Serrano-Maciá M, Lopitz-Otsoa F, Salas-Villalobos TB, Varela-Rey M, Delgado TC and Martínez-Chantar ML: Ubiquitin-like post-translational modifications (Ubl-PTMs): Small peptides with huge impact in liver fibrosis. Cells 8: 1575, 2019.

29. Dooley $S$ and Ten Dijke P: TGF- $\beta$ in progression of liver disease. Cell Tissue Res 347: 245-256, 2012.

30. Zhou C, York SR, Chen JY, Pondick JV, Motola DL, Chung RT and Mullen AC: Long noncoding RNAs expressed in human hepatic stellate cells form networks with extracellular matrix proteins. Genome Med 8: 31, 2016.

31. Li XQ, Ren ZX, Li K, Huang JJ, Huang ZT, Zhou TR, Cao HY, Zhang FX and Tan B: Key anti-fibrosis associated long noncoding RNAs identified in human hepatic stellate cell via transcriptome sequencing analysis. Int J Mol Sci 19: 675, 2018.

32. Kong Y, Huang T, Zhang H, Zhang Q, Ren J, Guo X, Fan H and Liu L: The lncRNA NEAT1/miR-29b/Atg9a axis regulates IGFBPrP1-induced autophagy and activation of mouse hepatic stellate cells. Life Sci 237: 116902, 2019.

33. Li XQ, Zhang QQ, Zhang HY, Guo XH, Fan HQ and Liu LX: Interaction between insulin-like growth factor binding protein-related protein 1 and transforming growth factor beta 1 in primary hepatic stellate cells. Hepatobiliary Pancreat Dis Int 16: 395-404, 2017.

34. Yu F, Jiang Z, Chen B, Dong P and Zheng J: NEAT1 accelerates the progression of liver fibrosis via regulation of microRNA-122 and Kruppel-like factor 6. J Mol Med (Berl) 95: 1191-1202, 2017.

35. Fu WM, Zhu X, Wang WM, Lu YF, Hu BG, Wang H, Liang WC Wang SS, Ko CH, Waye MM, et al: Hotair mediates hepatocarcinogenesis through suppressing miRNA-218 expression and activating P14 and P16 signaling. J Hepatol 63: 886-895, 2015.

36. Yu F, Chen B, Dong P and Zheng J: HOTAIR epigenetically modulates PTEN expression via MicroRNA-29b: A novel mechanism in regulation of liver fibrosis. Mol Ther 25: 205-217, 2017.

37. Zheng J, Mao Y, Dong P, Huang Z and Yu F: Long noncoding RNA HOTTIP mediates SRF expression through sponging miR-150 in hepatic stellate cells. J Cell Mol Med 23: 1572-1580, 2019.

38. Li Z, Wang J, Zeng Q, Hu C, Zhang J, Wang H, Yan J, Li H and Yu Z: Long noncoding RNA HOTTIP promotes mouse hepatic stellate cell activation via downregulating miR-148a. Cell Physiol Biochem 51: 2814-2828, 2018.

39. Wu Y, Liu X, Zhou Q, Huang C, Meng X, Xu F and Li J: Silent information regulator 1 (SIRT1) ameliorates liver fibrosis via promoting activated stellate cell apoptosis and reversion. Toxicol Appl Pharmacol 289: 163-176, 2015.

40. Yu F, Lu Z, Cai J, Huang K, Chen B, Li G, Dong P and Zheng J: MALAT1 functions as a competing endogenous RNA to mediate Racl expression by sequestering miR-101b in liver fibrosis. Cell Cycle 14: 3885-3896, 2015 .

41. Leti F, Legendre C, Still CD, Chu X, Petrick A, Gerhard GS and DiStefano JK: Altered expression of MALAT1 lncRNA in nonalcoholic steatohepatitis fibrosis regulates CXCL5 in hepatic stellate cells. Transl Res 190: 25-39. e21, 2017.

42. Shen X, Guo H, Xu J and Wang J: Inhibition of IncRNA HULC improves hepatic fibrosis and hepatocyte apoptosis by inhibiting the MAPK signaling pathway in rats with nonalcoholic fatty liver disease. J Cell Physiol 234: 18169-18179, 2019

43. Zhang K, Han Y, Hu Z, Zhang Z, Shao S, Yao Q, Zheng L, Wang J, Han X, Zhang Y, et al: SCARNA10, a nuclear-retained long non-coding RNA, promotes liver fibrosis and serves as a potential biomarker. Theranostics 9: 3622-3638, 2019.

44. Zhang K, Han X, Zhang Z, Zheng L, Hu Z, Yao Q, Cui H, Shu G, Si M, Li C, et al: The liver-enriched lnc-LFAR1 promotes liver fibrosis by activating TGF $\beta$ and Notch pathways. Nat Commun 8 : 144, 2017

45. Wu JC, Luo SZ, Liu T, Lu LG and Xu MY: Linc-SCRG1 accelerates liver fibrosis by decreasing RNA-binding protein tristetraprolin. FASEB J 33: 2105-2115, 2019.

46. Yu F, Dong P, Mao Y, Zhao B, Huang Z and Zheng J: Loss of lncRNA-SNHG7 promotes the suppression of hepatic stellate cell activation via miR-378a-3p and DVL2. Mol Ther Nucleic Acids 17: 235-244, 2019.
47. Zheng J, Yu F, Dong P, Wu L, Zhang Y, Hu Y and Zheng L: Long non-coding RNA PVT1 activates hepatic stellate cells through competitively binding microRNA-152. Oncotarget 7: 62886-62897, 2016.

48. Fu N, Zhao SX, Kong LB, Du JH, Ren WG, Han F, Zhang QS, Li WC, Cui P, Wang RQ, et al: LncRNA-ATB/microRNA-200a/ $\beta$-catenin regulatory axis involved in the progression of HCV-related hepatic fibrosis. Gene 618: 1-7, 2017.

49. Tu X, Zhang Y, Zheng X, Deng J, Li H, Kang Z, Cao Z, Huang Z, Ding Z, Dong L, et al: TGF- $\beta$-induced hepatocyte lincRNA-p21 contributes to liver fibrosis in mice. Sci Rep 7: 2957, 2017.

50. Yu F, Guo Y, Chen B, Shi L, Dong P, Zhou M and Zheng J: LincRNA-p21 inhibits the Wnt/ $\beta$-catenin pathway in activated hepatic stellate cells via sponging MicroRNA-17-5p. Cell Physiol Biochem 41: 1970-1980, 2017.

51. Yu F, Lu Z, Chen B, Dong $\mathrm{P}$ and Zheng J: Identification of a novel lincRNA-p21-miR-181b-PTEN signaling cascade in liver fibrosis. Mediators Inflamm 2016: 9856538, 2016.

52. Zheng J, Dong P, Mao Y, Chen S, Wu X, Li G, Lu Z and Yu F: Linc RNA-p21 inhibits hepatic stellate cell activation and liver fibrogenesis via p21. FEBS J 282: 4810-4821, 2015.

53. Yu F, Zhou G, Huang K, Fan X, Li G, Chen B, Dong P and Zheng J: Serum linc RNA-p21 as a potential biomarker of liver fibrosis in chronic hepatitis B patients. J Viral Hepat 24: 580-588, 2017.

54. He Y, Wu YT, Huang C, Meng XM, Ma TT, Wu BM, Xu FY, Zhang L, Lv XW and Li J: Inhibitory effects of long noncoding RNA MEG3 on hepatic stellate cells activation and liver fibrogenesis. Biochim Biophys Acta 1842: 2204-2215, 2014.

55. Chen MJ, Wang XG, Sun ZX and Liu XC: Diagnostic value of LncRNA-MEG3 as a serum biomarker in patients with hepatitis B complicated with liver fibrosis. Eur Rev Med Pharmacol Sci 23: 4360-4367, 2019.

56. Yu F, Geng W, Dong P, Huang Z and Zheng J: LncRNA-MEG3 inhibits activation of hepatic stellate cells through SMO protein and miR-212. Cell Death Dis 9: 1014, 2018.

57. Yu F, Zheng J, Mao Y, Dong P, Lu Z, Li G, Guo C, Liu Z and Fan X: Long non-coding RNA growth arrest-specific transcript 5 (GAS5) inhibits liver fibrogenesis through a mechanism of competing endogenous RNA. J Biol Chem 290: 28286-28298, 2015.

58. Zhou B, Yuan W and Li X: LncRNA Gm5091 alleviates alcoholic hepatic fibrosis by sponging miR-27b/23b/24 in mice. Cell Biol Int 42: 1330-1339, 2018.

59. Zhang QQ, Xu MY, Qu Y, Hu JJ, Li ZH, Zhang QD and Lu LG: TET3 mediates the activation of human hepatic stellate cells via modulating the expression of long non-coding RNA HIF1A-AS1. Int J Clin Exp Pathol 7: 7744-7751, 2014.

60. Yang JJ, Yang Y, Zhang C, Li J and Yang Y: Epigenetic silencing of LncRNA ANRIL enhances liver fibrosis and HSC activation through activating AMPK pathway. J Cell Mol Med 24: 2677-2687, 2020

61. Giovarelli M, Bucci G, Ramos A, Bordo D, Wilusz CJ, Chen CY, Puppo M, Briata P and Gherzi R: H19 long noncoding RNA controls the mRNA decay promoting function of KSRP. Proc Natl Acad Sci USA 111: E5023-E5028, 2014.

62. Liang WC, Fu WM, Wang YB, Sun YX, Xu LL, Wong CW, Chan KM, Li G, Waye MM and Zhang JF: H19 activates Wnt signaling and promotes osteoblast differentiation by functioning as a competing endogenous RNA. Sci Rep 6: 20121, 2016.

63. Li X, Liu R, Huang Z, Gurley EC, Wang X, Wang J, He H, Yang H, Lai G, Zhang L, et al: Cholangiocyte-derived exosomal long noncoding RNA H19 promotes cholestatic liver injury in mouse and humans. Hepatology 68: 599-615, 2018.

64. Yang JJ, She Q, Yang Y, Tao H and Li J: DNMT1 controls LncRNA H19/ERK signal pathway in hepatic stellate cell activation and fibrosis. Toxicol Lett 295: 325-334, 2018.

65. Yang JJ, Liu LP, Tao H, Hu W, Shi P, Deng ZY and Li J: MeCP2 silencing of LncRNA H19 controls hepatic stellate cell proliferation by targeting IGF1R. Toxicology 359-360: 39-46, 2016.

66. Song Y, Liu C, Liu X, Trottier J, Beaudoin M, Zhang L, Pope C, Peng $\mathrm{G}$, Barbier O, Zhong X, et al: $\mathrm{H} 19$ promotes cholestatic liver fibrosis by preventing ZEB1-mediated inhibition of epithelial cell adhesion molecule. Hepatology 66: 1183-1196, 2017.

67. Xiao Y, Liu R, Li X, Gurley EC, Hylemon PB, Lu Y, Zhou H and Cai W: Long noncoding RNA H19 contributes to cholangiocyte proliferation and cholestatic liver fibrosis in biliary atresia. Hepatology 70: 1658-1673, 2019.

68. Liu R, Li X, Zhu W, Wang Y, Zhao D, Wang X, Gurley EC, Liang G, Chen W, Lai G, et al: Cholangiocyte-derived exosomal long noncoding RNA H19 promotes hepatic stellate cell activation and cholestatic liver fibrosis. Hepatology 70: 1317-1335, 2019. 
69. Fernandes JCR, Acuña SM, Aoki JI, Floeter-Winter LM and Muxel SM: Long non-coding RNAs in the regulation of gene expression: Physiology and disease. Noncoding RNA 5: 17, 2019.

70. Xu F, Liu C, Zhou D and Zhang L: TGF- $\beta /$ SMAD pathway and its regulation in hepatic fibrosis. J Histochem Cytochem 64: 157-167, 2016.

71. Fabregat I, Moreno-Càceres J, Sánchez A, Dooley S, Dewidar B, Giannelli G and Ten Dijke P; IT-LIVER Consortium: TGF-beta signalling and liver disease. FEBS J 283: 2219-2232, 2016.

72. Caja L, Dituri F, Mancarella S, Caballero-Diaz D, Moustakas A, Giannelli $\mathrm{G}$ and Fabregat I: TGF- $\beta$ and the tissue microenvironment: Relevance in fibrosis and cancer. Int J Mol Sci 19: 1294, 2018.

73. Martens L, Rühle F and Stoll M: LncRNA secondary structure in the cardiovascular system. Noncoding RNA Res 2: 137-142, 2017.

74. Zampetaki A, Albrecht A and Steinhofel K: Long non-coding RNA structure and function: Is there a link? Front Physiol 9: 1201, 2018.

75. He Z, Yang D, Fan X, Zhang M, Li Y, Gu X and Yang M: The roles and mechanisms of lncRNAs in liver fibrosis. Int J Mol Sci 21: 1482, 2020.

76. Kuo CC, Hänzelmann S, Sentürk Cetin N, Frank S, Zajzon B, Derks JP, Akhade VS, Ahuja G, Kanduri C, Grummt I, et al: Detection of RNA-DNA binding sites in long noncoding RNAs. Nucleic Acids Res 47: e32, 2019.

77. Teng KY and Ghoshal K: Role of noncoding RNAs as biomarker and therapeutic targets for liver fibrosis. Gene Expr 16: 155-162, 2015.

78. Roderburg C, Mollnow $\mathrm{T}$, Bongaerts B, Elfimova $\mathrm{N}$, Vargas Cardenas D, Berger K, Zimmermann H, Koch A, Vucur M, Luedde M, et al: Micro-RNA profiling in human serum reveals compartment-specific roles of miR-571 and miR-652 in liver cirrhosis. PLoS One 7: e32999, 2012.

79. Klose RJ and Bird AP: Genomic DNA methylation: The mark and its mediators. Trends Biochem Sci 31: 89-97, 2006.

80. Shang Z, Yu J, Sun L, Tian J, Zhu S, Zhang B, Dong Q, Jiang N, Flores-Morales A, Chang C and Niu Y: LncRNA PCAT1 activates $\mathrm{AKT}$ and $\mathrm{NF}-\kappa \mathrm{B}$ signaling in castration-resistant prostate cancer by regulating the PHLPP/FKBP51/IKK $\alpha$ complex. Nucleic Acids Res 47: 4211-4225, 2019.

81. Gujar H, Weisenberger DJ and Liang G: The roles of human DNA methyltransferases and their isoforms in shaping the epigenome. Genes (Basel) 10: 172, 2019.

82. Edwards JR, Yarychkivska O, Boulard M and Bestor TH DNA methylation and DNA methyltransferases. Epigenetics Chromatin 10: 23, 2017.

83. Arand J, Spieler D, Karius T, Branco MR, Meilinger D, Meissner A, Jenuwein T, Xu G, Leonhardt $\mathrm{H}$, Wolf $\mathrm{V}$ and Walter J: In vivo control of CpG and non-CpG DNA methylation by DNA methyltransferases. PLoS Genet 8: e1002750, 2012.

84. Okano M, Bell DW, Haber DA and Li E: DNA methyltransferases Dnmt3a and Dnmt3b are essential for de novo methylation and mammalian development. Cell 99: 247-257, 1999.

85. Du J, Johnson LM, Jacobsen SE and Patel DJ: DNA methylation pathways and their crosstalk with histone methylation. Nat Rev Mol Cell Biol 16: 519-532, 2015.

86. Page A, Mann DA and Mann J: The mechanisms of HSC activation and epigenetic regulation of HSCs phenotypes. Curr Pathobiol Rep 2: 163-170, 2014.

87. Wilson CL, Mann DA and Borthwick LA: Epigenetic reprogramming in liver fibrosis and cancer. Adv Drug Deliv Rev 121: 124-132, 2017.

88. Dowson C and O'Reilly S: DNA methylation in fibrosis. Eur J Cell Biol 95: 323-330, 2016

89. Mann J, Oakley F, Akiboye F, Elsharkawy A, Thorne AW and Mann DA: Regulation of myofibroblast transdifferentiation by DNA methylation and MeCP2: Implications for wound healing and fibrogenesis. Cell Death Differ 14: 275-285, 2007.

90. Komatsu Y, Waku T, Iwasaki N, Ono W, Yamaguchi C and Yanagisawa J: Global analysis of DNA methylation in early-stage liver fibrosis. BMC Med Genomics 5: 5, 2012.

91. Götze S, Schumacher EC, Kordes C and Häussinger D: Epigenetic changes during hepatic stellate cell activation. PLoS One 10: e0128745, 2015.

92. El Taghdouini A, Sørensen AL, Reiner AH, Coll M, Verhulst S, Mannaerts I, Øie CI, Smedsrød B, Najimi M, Sokal E, et al: Genome-wide analysis of DNA methylation and gene expression patterns in purified, uncultured human liver cells and activated hepatic stellate cells. Oncotarget 6: 26729-26745, 2015.
93. Xiong WJ, Hu LJ, Jian YC, Wang LJ, Jiang M, Li W and He Y: Wnt5a participates in hepatic stellate cell activation observed by gene expression profile and functional assays. World J Gastroenterol 18: 1745-1752, 2012.

94. Miao CG, Yang YY, He X, Huang C, Huang Y, Zhang L, Lv XW, Jin Y and Li J: Wnt signaling in liver fibrosis: Progress, challenges and potential directions. Biochimie 95: 2326-2335, 2013.

95. Jiang F, Parsons CJ and Stefanovic B: Gene expression profile of quiescent and activated rat hepatic stellate cells implicates Wnt signaling pathway in activation. J Hepatol 45: 401-409, 2006.

96. Bian EB, Huang C, Wang H, Chen XX, Zhang L, Lv XW and Li J: Repression of Smad7 mediated by DNMT1 determines hepatic stellate cell activation and liver fibrosis in rats. Toxicol Lett 224: 175-185, 2014.

97. Bian EB, Huang C, Ma TT, Tao H, Zhang H, Cheng C, Lv XW and Li J: DNMT1-mediated PTEN hypermethylation confers hepatic stellate cell activation and liver fibrogenesis in rats. Toxicol Appl Pharmacol 264: 13-22, 2012.

98. Page A, Paoli PP, Hill SJ, Howarth R, Wu R, Kweon SM, French J, White S, Tsukamoto H, Mann DA and Mann J: Alcohol directly stimulates epigenetic modifications in hepatic stellate cells. J Hepatol 62: 388-397, 2015.

99. Tian W, Fan Z, Li J, Hao C, Li M, Xu H, Wu X, Zhou B, Zhang L, Fang $\mathrm{M}$ and $\mathrm{Xu} \mathrm{Y}$ : Myocardin-related transcription factor A (MRTF-A) plays an essential role in hepatic stellate cell activation by epigenetically modulating TGF- $\beta$ signaling. Int J Biochem Cell Biol 71: 35-43, 2016.

100. Gregory GD, Vakoc CR, Rozovskaia T, Zheng X, Patel S, Nakamura T, Canaani E and Blobel GA: Mammalian ASH1L is a histone methyltransferase that occupies the transcribed region of active genes. Mol Cell Biol 27: 8466-8479, 2007.

101. Perugorria MJ, Wilson CL, Zeybel M, Walsh M, Amin S, Robinson S, White SA, Burt AD, Oakley F, Tsukamoto H, et al: Histone methyltransferase ASH1 orchestrates fibrogenic gene transcription during myofibroblast transdifferentiation. Hepatology 56: 1129-1139, 2012.

102. Cao R and Zhang Y: The functions of $\mathrm{E}(\mathrm{Z}) / \mathrm{EZH} 2$-mediated methylation of lysine 27 in histone H3. Curr Opin Genet Dev 14: 155-164, 2004

103. Mann J, Chu DC, Maxwell A, Oakley F, Zhu NL, Tsukamoto H and Mann DA: MeCP2 controls an epigenetic pathway that promotes myofibroblast transdifferentiation and fibrosis. Gastroenterology 138: 705-714, 714.e1-4, 2010

104. Martin-Mateos R, De Assuncao TM, Arab JP,Jalan-Sakrikar N, Yaqoob U, Greuter T, Verma VK, Mathison AJ, Cao S, Lomberk G, et al: Enhancer of zeste homologue 2 inhibition attenuates TGF- $\beta$ dependent hepatic stellate cell activation and liver fibrosis. Cell Mol Gastroenterol Hepatol 7: 197-209, 2019.

105. Panebianco C, Oben JA, Vinciguerra $M$ and Pazienza V: Senescence in hepatic stellate cells as a mechanism of liver fibrosis reversal: A putative synergy between retinoic acid and PPAR-gamma signalings. Clin Exp Med 17: 269-280, 2017.

106. Schwartz YB and Pirrotta V: Polycomb silencing mechanisms and the management of genomic programmes. Nat Rev Genet 8: 9-22, 2007

107. Hammond CM, Strømme CB, Huang H, Patel DJ and Groth A: Histone chaperone networks shaping chromatin function. Nat Rev Mol Cell Biol 18: 141-158, 2017.

108. Mannaerts I, Nuytten NR, Rogiers V, Vanderkerken K, van Grunsven LA and Geerts A: Chronic administration of valproic acid inhibits activation of mouse hepatic stellate cells in vitro and in vivo. Hepatology 51: 603-614, 2010.

109. Mannaerts I, Eysackers N, Onyema OO, Van Beneden K, Valente S, Mai A, Odenthal M and van Grunsven LA: Class II HDAC inhibition hampers hepatic stellate cell activation by induction of microRNA-29. PLoS One 8: e55786, 2013.

110. Shaker ME, Ghani A, Shiha GE, Ibrahim TM and Mehal WZ: Nilotinib induces apoptosis and autophagic cell death of activated hepatic stellate cells via inhibition of histone deacetylases. Biochim Biophys Acta 1833: 1992-2003, 2013.

111. Duarte S, Baber J, Fujii T and Coito AJ: Matrix metalloproteinases in liver injury, repair and fibrosis. Matrix Biol 44-46 147-156, 2015.

112. Qin L and Han YP: Epigenetic repression of matrix metalloproteinases in myofibroblastic hepatic stellate cells through histone deacetylases 4: Implication in tissue fibrosis. Am J Pathol 177: 1915-1928, 2010. 
113. Ding G, Li W, Liu J, Zeng Y, Mao C, Kang Y and Shang J: LncRNA GHET1 activated by H3K27 acetylation promotes cell tumorigenesis through regulating ATF1 in hepatocellular carcinoma. Biomed Pharmacother 94: 326-331, 2017.

114. Yang F, Huo XS, Yuan SX, Zhang L, Zhou WP, Wang F and Sun SH: Repression of the long noncoding RNA-LET by histone deacetylase 3 contributes to hypoxia-mediated metastasis. Mol Cell 49: 1083-1096, 2013.

115. Pope C, Mishra S, Russell J, Zhou Q and Zhong XB: Targeting H19, an imprinted long non-coding RNA, in hepatic functions and liver diseases. Diseases 5: 11, 2017.

116. Zhu XT, Yuan JH, Zhu TT, Li YY and Cheng XY: Long noncoding RNA glypican 3 (GPC3) antisense transcript 1 promotes hepatocellular carcinoma progression via epigenetically activating GPC3. FEBS J 283: 3739-3754, 2016.

117. Issa JJ, Roboz G, Rizzieri D, Jabbour E, Stock W, O'Connell C, Yee K, Tibes R, Griffiths EA, Walsh K, et al: Safety and tolerability of guadecitabine (SGI-110) in patients with myelodysplastic syndrome and acute myeloid leukaemia: A multicentre, randomised, dose-escalation phase 1 study. Lancet Oncol 16: 1099-1110, 2015.

118. Jansen YJL, Verset G, Schats K, Van Dam PJ, Seremet T, Kockx M, Van Laethem JB and Neyns B: Phase I clinical trial of decitabine (5-aza-2'-deoxycytidine) administered by hepatic arterial infusion in patients with unresectable liver-predominant metastases. ESMO Open 4: e000464, 2019.

119. Kuang Y,El-Khoueiry A, Taverna P, Ljungman M and Neamati N: Guadecitabine (SGI-110) priming sensitizes hepatocellular carcinoma cells to oxaliplatin. Mol Oncol 9: 1799-1814, 2015.

120. Eckschlager T, Plch J, Stiborova M and Hrabeta J: Histone deacetylase inhibitors as anticancer drugs. Int J Mol Sci 18: 1414, 2017.

121. Park KC, Park JH, Jeon JY, Kim SY, Kim JM, Lim CY, Lee TH, Kim HK, Lee HG, Kim SM, et al: A new histone deacetylase inhibitor improves liver fibrosis in BDL rats through suppression of hepatic stellate cells. Br J Pharmacol 171: 4820-4830, 2014

122. Liu Y, Wang Z, Wang J, Lam W, Kwong S, Li F, Friedman SL, Zhou S, Ren Q, Xu Z, et al: A histone deacetylase inhibitor, largazole, decreases liver fibrosis and angiogenesis by inhibiting transforming growth factor- $\beta$ and vascular endothelial growth factor signalling. Liver Int 33: 504-515, 2013.

123. Watanabe T, Tajima H, Hironori H, Nakagawara H, Ohnishi I, Takamura H, Ninomiya I, Kitagawa H, Fushida S, Tani T, et al: Sodium valproate blocks the transforming growth factor (TGF)- $\beta 1$ autocrine loop and attenuates the TGF- $\beta 1$-induced collagen synthesis in a human hepatic stellate cell line. Int J Mol Med 28: 919-925, 2011.
124. Niki T, Rombouts K, De Bleser P, De Smet K, Rogiers V, Schuppan D, Yoshida M, Gabbiani G and Geerts A: A histone deacetylase inhibitor, trichostatin A, suppresses myofibroblastic differentiation of rat hepatic stellate cells in primary culture. Hepatology 29: 858-867, 1999.

125. Ding D, Chen LL, Zhai YZ, Hou CJ, Tao LL, Lu SH, Wu J and Liu XP: Trichostatin A inhibits the activation of Hepatic stellate cells by Increasing C/EBP- $\alpha$ Acetylation in vivo and in vitro. Sci Rep 8: 4395, 2018

126. Smith $\mathrm{E}$ and Shilatifard A: The chromatin signaling pathway: Diverse mechanisms of recruitment of histone-modifying enzymes and varied biological outcomes. Mol Cell 40: 689-701, 2010.

127. Yadav T, Quivy JP and Almouzni G: Chromatin plasticity: A versatile landscape that underlies cell fate and identity. Science 361: 1332-1336, 2018.

128. Hu B, Gharaee-Kermani M, Wu Z and Phan SH: Essential role of MeCP2 in the regulation of myofibroblast differentiation during pulmonary fibrosis. Am J Pathol 178: 1500-1508, 2011.

129. Bian EB, Huang C, Wang H, Chen XX, Tao H, Zhang L, Lv XW and $\mathrm{Li}$ J: The role of methyl-CpG binding protein 2 in liver fibrosis. Toxicology 309: 9-14, 2013.

130. Mellén M, Ayata P, Dewell S, Kriaucionis S and Heintz N: $\mathrm{MeCP} 2$ binds to $5 \mathrm{hmC}$ enriched within active genes and accessible chromatin in the nervous system. Cell 151: 1417-1430, 2012.

131. Bárcena-Varela M, Caruso S, Llerena S, Álvarez-Sola G, Uriarte I, Latasa MU, Urtasun R, Rebouissou S, Alvarez L, Jimenez M, et al: Dual targeting of histone methyltransferase G9a and DNA-Methyltransferase 1 for the treatment of experimental hepatocellular carcinoma. Hepatology 69: 587-603, 2019.

132. Moran-Salvador E, Garcia-Macia M, Sivaharan A, Sabater L, Zaki MYW, Oakley F, Knox A, Page A, Luli S, Mann J and Mann DA: Fibrogenic activity of MECP2 is regulated by phosphorylation in hepatic stellate cells. Gastroenterology 157: 1398-1412.e9, 2019.

133. Florean C: Food that shapes you: How diet can change your epigenome. Science in School: May 13, 2014 (Epub ahead of print)

134. Yang JJ, Tao H,Deng ZY,LuCand LiJ: Non-coding RNA-mediated epigenetic regulation of liver fibrosis. Metabolism 64: 1386-1394, 2015.

135. Jiang X, Tsitsiou E, Herrick SE and Lindsay MA: MicroRNAs and the regulation of fibrosis. FEBS J 277: 2015-2021, 2010. 